\title{
Association between a Variant in MicroRNA-646 and the Susceptibility to Hepatocellular Carcinoma in a Large-Scale Population
}

\author{
Rui Wang, ${ }^{1,2}$ Jun Zhang, ${ }^{1}$ Weiru Jiang, ${ }^{1}$ Yanyun Ma, ${ }^{3}$ Wenshuai Li, ${ }^{1}$ Bohan Jin, ${ }^{1}$ \\ Heping Hu, ${ }^{4}$ Jiucun Wang, ${ }^{3}$ Yi Liu, ${ }^{1}$ and Jie Liu ${ }^{1,2}$ \\ ${ }^{1}$ Department of Digestive Diseases, Huashan Hospital, Fudan University, 12 Middle Wulumuqi Road, Shanghai 200040, China \\ ${ }^{2}$ Department of Immunology of Shanghai Medical School and Institutes of Biomedical Sciences, Fudan University, \\ Shanghai 200032, China \\ ${ }^{3}$ Ministry of Education Key Laboratory of Contemporary Anthropology and State Key Laboratory of Genetic Engineering, \\ School of Life Sciences, Fudan University, Shanghai 200433, China \\ ${ }^{4}$ Eastern Hepatobiliary Surgery Hospital, Second Military Medical University, Shanghai 200438, China
}

Correspondence should be addressed to Yi Liu; liuyi0205@sina.com and Jie Liu; jieliu@fudan.edu.cn

Received 23 March 2014; Revised 6 July 2014; Accepted 21 July 2014; Published 7 August 2014

Academic Editor: Manuela Ferracin

Copyright (C) 2014 Rui Wang et al. This is an open access article distributed under the Creative Commons Attribution License, which permits unrestricted use, distribution, and reproduction in any medium, provided the original work is properly cited.

Background. Single-nucleotide polymorphisms in microRNAs play important roles in oncogenesis and cancer development. Objective. We aim to explore whether miR-646 rs6513497 is associated with the risk of hepatocellular carcinoma. Methods. Total 997 HCC patients and 993 cancer-free controls were enrolled in this study. Genotyping was performed using MassARRAY method. Results. Compared with the T allele of rs6513497, the G allele was associated with a significantly decreased risk of HCC $(\mathrm{OR}=0.788$, $95 \% \mathrm{CI}=0.631-0.985, P=0.037)$; moreover, a more protective effect of the $\mathrm{G}$ allele was shown in males $(\mathrm{OR}=0.695,95 \% \mathrm{CI}=$ $0.539-0.897, P=0.005$ in HCC and $\mathrm{OR}=0.739,95 \% \mathrm{CI}=0.562-0.972, P=0.030$ in HBV-related HCC), basically in a dominant manner (HCC: $\mathrm{OR}=0.681,95 \% \mathrm{CI}=0.162-0.896, P=0.006$; HBV-related HCC: $\mathrm{OR}=0.715,95 \% \mathrm{CI}=0.532-0.962, P=0.027$ ). Conclusions. Our findings support the view that the miR-646 SNP rs6513497 may contribute to the susceptibility of HCC.

\section{Introduction}

Hepatocellular carcinoma (HCC) is one of the most prevalent cancers and is the third leading cause of cancer-related death due to its extremely poor prognosis [1]. Both genetic and environmental factors can contribute to the occurrence of $\mathrm{HCC}$. The chronic infection of the Hepatitis $\mathrm{B}$ or $\mathrm{C}$ virus is the main risk factor for HCC, while alcohol abuse, smoking, or exposure to toxic substances is also found to have the potential to increase the risk of HCC [2].

MicroRNA (miRNA) is a class of single-stranded, 1925 nucleotides in length, noncoding RNA molecules in eukaryotes. Binding to the $3^{\prime}$ - untranslated region ( $3^{\prime}$-UTR) of target mRNAs, miRNA regulates the translation and degradation of its target mRNAs and thus influences the gene expression $[3,4]$. More and more evidence has shown that miRNAs are strongly related to oncogenesis $[5,6]$. It has been shown that miRNAs play critical roles in tumor suppression or carcinogenesis by regulating gene expression at posttranscriptional levels [7]. A large number of tumorderived microRNAs exist in human serum/plasma in a stable, reproducible, and consistent form, which thus can serve as potential biomarkers for blood-based detection of human cancers $[8,9]$. Therefore, as a regulatory molecule, miRNA offers us a new diagnostic approach for cancers. Indeed, a recent study screened a plasma microRNA panel and identified several miRNAs which showed high effectiveness and accuracy in HCC diagnosis [10]. Such inspiring result pushed forward the development of the early detection of HCC based on microRNA.

Single-nucleotide polymorphisms (SNPs), one form of DNA variation, are pervasive in miRNAs, including 
pri-miRNAs, pre-miRNAs, and mature miRNAs. They could influence various biological processes by changing the secondary structure of pre-miRNAs, interfering the maturation and/or target selection of miRNAs $[11,12]$, and may thus play roles in the development and progression of some cancers.

Previous studies have shown that miR-646 is implicated in human cancers $[13,14]$. Moreover, the SNPs in miR-646, rs112880289, rs6513496, and rs6513497, have been reported to be associated with the susceptibility to colorectal cancer [15]. Thus, it is worth questioning whether these SNPs are associated with HCC as well. However, rs112880289 is not valid in Han Chinese people while rs6513496 seems to have no effect on the structural stability of miR-646 precursor $(\Delta \Delta G<0 \mathrm{KJ} / \mathrm{mol}$ calculated by miRNASNP database [16]). Thus, the aim of this study is to investigate the clinical significance of the miR-646 SNP rs6513497 in human HCC, by analyzing a case-control Chinese population of 997 HCC patients and 993 cancer-free controls.

\section{Materials and Methods}

2.1. Study Population. Subjects were recruited from a casecontrol Chinese population as described previously [17]. In brief, patients from Huashan Hospital Affiliated to Fudan University and Eastern Hepatobiliary Surgery Hospital were diagnosed with HCC by a pathological examination or afetoprotein elevation $(>20 \mathrm{ug} / \mathrm{L})$ combined with imaging examination (magnetic resonance imaging, MRI and/or computerized tomography, CT). Cancer-free controls from the Taizhou Longitudinal Study had no self-reported history of cancer. All subjects including both cases and controls were unrelated Chinese Han individuals residing in East China (Shanghai, Zhejiang, Jiangsu, and Jiangxi province). All patient materials including peripheral blood samples were obtained with informed consent, and the whole procedure was approved by local ethic review committee.

2.2. Genotyping. Genomic DNA was isolated from the peripheral blood of the participants using AxyPrep Blood Genomic DNA Miniprep Kit (Axygen Biosciences, Union City, USA). Genotyping was done using Sequenom MassARRAY technique. The amplification primers were $5^{\prime}$ ACGTTGGATGCACACCTGCTTTTCACCTGT- ${ }^{\prime}$ and $5^{\prime}$ ACGTTGGATGGTAAAGATAGGCCACTGAGC-3' , while the extension primer was $5^{\prime}$-CCCCCAGGAAGCAGCTGCCTC- $3^{\prime}$.

2.3. Statistical Analysis. Statistical analyses were performed using SPSS (version 13.0) and Excel. Observed and expected genotype frequencies were evaluated for Hardy-Weinberg equilibrium (HWE) using Pearson's chi-square test. Odds ratio (OR) adjusted for age, gender, smoking status, and drinking status, along with 95\% confidence interval (CI), was determined by logistic regression. Pearson's chi-square test was also used to assess qualitative data among different groups, while Student's $t$-test and nonparametric test were applied to compare quantitative variables. A two-sided $P$ value less than 0.05 was considered statistically significant.

\section{Results}

3.1. Sample Overview. 997 HCC patients (including 771 HBV-related HCC patients) and 993 controls were enrolled in this study. The demographic characteristics were summarized in Table 1. Briefly, it was shown that age, gender, and smoking status were significantly different between the cases and the controls (controls older than cases), while drinking status was no different between two groups.

3.2. Association between the miR-646 Variant and the Susceptibility to Hepatocellular Carcinoma. The genotype distributions of rs6513497 in controls, HCC patients, and HBVrelated HCC patients are shown in Table 2. In the logistic regression analysis between $\mathrm{HCC}$ and the control subjects, it was shown that in comparison with the T allele of rs6513497, the $\mathrm{G}$ allele were associated with a significantly decreased risk of $\mathrm{HCC}(\mathrm{OR}=0.788,95 \% \mathrm{CI}=0.631-0.985, P=0.037)$.

In males (Table 3 ), some much more significant associations were found. Firstly, in comparison with the $\mathrm{T}$ allele of rs6513497, the $\mathrm{G}$ allele were associated with a greater decreased risk of HCC (adjusted OR $=0.695,95 \% \mathrm{CI}=$ 0.539-0.897, $P=0.005$ ) and HBV-related HCC (adjusted $\mathrm{OR}=0.739,95 \% \mathrm{CI}=0.562-0.972, P=0.030)$. Secondly, compared with the wild type TT of rs6513497, those with the GT genotype also have a decreased risk for HCC (adjusted OR of $0.692,95 \% \mathrm{CI}=0.523-0.915, P=0.010)$ and HBVrelated HCC (adjusted OR of $0.719,95 \% \mathrm{CI}=0.531-0.973$, $P=0.033$ ). Thirdly, we found that dominant model was suitable for the association between rs6513497 and the risk of HCC $(\mathrm{OR}=0.681,95 \% \mathrm{CI}=0.162-0.896, P=0.006)$ or HBV-related HCC $(\mathrm{OR}=0.715,95 \% \mathrm{CI}=0.532-0.962$, $P=0.027)$. Nevertheless, no association was founded in female subjects (Table 4).

3.3. Association between rs6513497 and Demographic Characteristic in HCC Patients. The association between rs6513497 and HCC or HBV infection was also evaluated by stratifying on other clinical indexes including total bilirubin, HBVDNA, ALT, AST, and the number, size, and grade of tumor foci. However, no significant heterogeneity was detected between the subgroups, suggesting the independent genetic effect of rs6513497 (Table 5).

\section{Discussion}

Traditional diagnostic methods of HCC have suboptimal efficacy, sensitivity, and specificity [18, 19]. The demand of outstanding biomarkers and innovational methods with high validity and efficacy is extremely urgent [20]. The growing evidence has shown that microRNA, as a new tumor biomarker, has considerable potential to improve the accuracy of early diagnosis of HCC $[21,22]$. For example, the plasma miRNA panel had high predictive accuracy for earlystaged HCC [10], suggesting that miRNA could be served as a valid and noninvasive method for prediction and diagnosis of HCC. Besides, it has been well acknowledged that microRNA SNPs have relevance to the susceptibility to cancers [23, 
TABLE 1: General characteristics in hepatocellular carcinoma patients and controls.

\begin{tabular}{|c|c|c|c|}
\hline & $\begin{array}{c}\text { Cases }(n=997) \\
\text { Number }(\%) \text { or mean } \pm \text { SD }\end{array}$ & $\begin{array}{c}\text { Controls }(n=993) \\
\text { Number }(\%) \text { or mean } \pm \text { SD }\end{array}$ & $P$ value \\
\hline Age (years) & $54.70 \pm 11.27$ & $59.57 \pm 11.65$ & $<0.001^{*}$ \\
\hline \multicolumn{4}{|l|}{ Gender } \\
\hline Male & $819(82.1)$ & $721(72.6)$ & \multirow{2}{*}{$<0.001^{*}$} \\
\hline Female & $178(17.9)$ & $272(27.4)$ & \\
\hline \multicolumn{4}{|l|}{ Smoking status } \\
\hline Never & $665(67.6)$ & $527(53.1)$ & \multirow{2}{*}{$<0.001^{*}$} \\
\hline Ever & $319(32.4)$ & $466(46.9)$ & \\
\hline \multicolumn{4}{|l|}{ Drinking status } \\
\hline Never & $734(74.4)$ & $732(73.7)$ & \multirow{2}{*}{0.712} \\
\hline Ever & $252(25.6)$ & $261(26.3)$ & \\
\hline \multicolumn{4}{|l|}{ HBsAg $(n=951)$} \\
\hline Negative & $180(18.9)$ & & \\
\hline Positive & $771(81.1)$ & & \\
\hline \multicolumn{4}{|l|}{ Tumor size $(n=540)$} \\
\hline$<5 \mathrm{~cm}$ & $218(40.4)$ & & \\
\hline$\geq 5 \mathrm{~cm}$ & $322(59.6)$ & & \\
\hline \multicolumn{4}{|l|}{ Tumor number $(n=539)$} \\
\hline Single & $475(88.1)$ & & \\
\hline Multiple & $64(11.9)$ & & \\
\hline \multicolumn{4}{|l|}{ Tumor grade $(n=385)$} \\
\hline I-II & $84(21.8)$ & & \\
\hline III-IV & $301(78.2)$ & & \\
\hline \multicolumn{4}{|l|}{ Serum level of tumor markers } \\
\hline ALT (U/L, in 989 subjects) & $58.29 \pm 86.04$ & & \\
\hline AST (U/L, in 985 subjects) & $62.24 \pm 81.06$ & & \\
\hline \multicolumn{4}{|l|}{ AFP } \\
\hline$<20 \mathrm{ug} / \mathrm{L}$ & $363(37.2)$ & & \\
\hline$\geq 20 \mathrm{ug} / \mathrm{L}$ & $612(62.8)$ & & \\
\hline (ug/L, in 404 subjects) & $126.87 \pm 289.61(0.6-1210)$ & & \\
\hline HBV-DNA (IU/mL, in 450 subjects) & $1.742 E 06 \pm 5.430 E 06(1000-6.9 E 07)$ & & \\
\hline
\end{tabular}

${ }^{*} P$ value less than 0.05 .

TABLE 2: Association between genotypes/alleles of miR-646 rs6513497 and the risk of HCC.

\begin{tabular}{|c|c|c|c|c|c|c|c|}
\hline \multirow{2}{*}{ Genotypes } & \multirow{2}{*}{$\begin{array}{c}\text { Controls } \\
\text { Number (\%) }\end{array}$} & \multicolumn{3}{|c|}{ HCC patients } & \multicolumn{3}{|c|}{ HCC patients with HBV } \\
\hline & & Number (\%) & OR $(95 \% \mathrm{CI})^{\mathrm{a}}$ & $P$ value $^{\mathrm{a}}$ & Number (\%) & OR $(95 \% \mathrm{CI})^{\mathrm{a}}$ & $P$ value $^{\mathrm{a}}$ \\
\hline miR-646 rs6513497 & $n=993$ & $n=997$ & & & $n=771$ & & \\
\hline $\mathrm{TT}$ & $795(80.1)$ & $825(82.7)$ & 1.000 & & $639(82.9)$ & 1.000 & \\
\hline GT & $186(18.7)$ & $166(16.6)$ & $0.812(0.635-1.037)$ & 0.095 & $126(16.3)$ & $0.814(0.621-1.067)$ & 0.137 \\
\hline GG & $12(12.2)$ & $6(0.6)$ & $0.468(0.167-1.308)$ & 0.147 & $6(0.8)$ & $0.631(0.222-1.793)$ & 0.387 \\
\hline $\begin{array}{l}\text { Dominant model } \\
\text { (TT versus GT }+ \text { GG) }\end{array}$ & & & $0.791(0.622-1.005)$ & 0.055 & & $0.803(0.616-1.046)$ & 0.104 \\
\hline $\begin{array}{l}\text { Recessive model } \\
(\mathrm{TT}+\mathrm{GT} \text { versus GG) }\end{array}$ & & & $0.485(0.174-1.355)$ & 0.168 & & $0.654(0.230-1.856)$ & 0.425 \\
\hline $\mathrm{T}$ & $1776(0.9)$ & $1816(0.9)$ & 1.000 & & $1402(91.0)$ & 1.000 & \\
\hline G & $210(0.1)$ & $178(0.1)$ & $0.788(0.631-0.985)$ & $0.037^{*}$ & $138(9.0)$ & $0.814(0.637-1.039)$ & 0.098 \\
\hline
\end{tabular}

${ }^{\mathrm{a}} \mathrm{ORs}$ and $P$ values were all obtained after adjusting for age, gender, smoking status, and wine status.

${ }^{*} P$ value less than 0.05 . 
TABLE 3: Comparison of genotype/allele frequencies of miR-646 rs6513497 in male subjects.

\begin{tabular}{|c|c|c|c|c|c|c|c|}
\hline \multirow{2}{*}{ Genotypes } & \multirow{2}{*}{$\begin{array}{c}\text { Controls } \\
\text { Number (\%) }\end{array}$} & \multicolumn{3}{|c|}{ HCC patients } & \multicolumn{3}{|c|}{ HCC patients with HBV } \\
\hline & & Number (\%) & OR $(95 \% \text { CI })^{\mathrm{a}}$ & $P$-value ${ }^{\mathrm{a}}$ & Number (\%) & OR $(95 \% \mathrm{CI})^{\mathrm{a}}$ & $P$ value ${ }^{\mathrm{a}}$ \\
\hline miR-646 rs6513497 & $n=721$ & $n=819$ & & & $n=643$ & & \\
\hline $\mathrm{TT}$ & $570(79.1)$ & $685(83.6)$ & 1.000 & & $536(83.4)$ & 1.000 & \\
\hline GT & $143(19.8)$ & $129(15.8)$ & $0.692(0.523-0.915)$ & $0.010^{*}$ & $102(15.9)$ & $0.719(0.531-0.973)$ & $0.033^{*}$ \\
\hline GG & $8(1.1)$ & $5(0.6)$ & $0.492(0.151-1.596)$ & 0.237 & $5(0.7)$ & $0.650(0.198-2.134)$ & 0.478 \\
\hline $\begin{array}{l}\text { Dominant model } \\
\text { (TT versus GT + GG) }\end{array}$ & & & $0.681(0.517-0.896)$ & $0.006^{*}$ & & $0.715(0.532-0.962)$ & $0.027^{*}$ \\
\hline $\begin{array}{l}\text { Recessive model } \\
(\mathrm{TT}+\mathrm{GT} \text { versus GG) }\end{array}$ & & & $0.525(0.162-1.701)$ & $0.023^{*}$ & & $0.690(0.211-2.259)$ & 0.540 \\
\hline $\mathrm{T}$ & $1283(89.0)$ & $1499(91.5)$ & 1.000 & & $1172(91.3)$ & 1.000 & \\
\hline G & $159(11.0)$ & $139(8.5)$ & $0.695(0.539-0.897)$ & $0.005^{*}$ & $112(8.7)$ & $0.739(0.562-0.972)$ & $0.030^{*}$ \\
\hline
\end{tabular}

${ }^{\mathrm{a}}$ ORs and $P$ values were obtained after the adjustment of age, gender, smoking status, and wine status.

${ }^{*} P$ value less than 0.05 .

TABLE 4: Comparison of genotype/allele frequencies of miR-646 rs6513497 in female subjects.

\begin{tabular}{|c|c|c|c|c|c|c|c|}
\hline \multirow{2}{*}{ Genotypes } & \multirow{2}{*}{$\begin{array}{c}\text { Controls } \\
\text { Number (\%) }\end{array}$} & \multicolumn{3}{|c|}{ HCC patients } & \multicolumn{3}{|c|}{ HCC patients with HBV } \\
\hline & & Number (\%) & OR $(95 \% \text { CI })^{\mathrm{a}}$ & $P$ value $^{\mathrm{a}}$ & Number (\%) & OR $(95 \% \mathrm{CI})^{\mathrm{a}}$ & $P$ value $^{\mathrm{a}}$ \\
\hline miR-646 rs6513497 & $n=272$ & $n=178$ & & & $n=128$ & & \\
\hline $\mathrm{TT}$ & $225(82.7)$ & $140(78.7)$ & 1.000 & & $103(80.5)$ & 1.000 & \\
\hline GT & $43(15.8)$ & $37(20.8)$ & $1.355(0.817-2.246)$ & 0.239 & $24(18.8)$ & $1.318(0.727-2.389)$ & 0.363 \\
\hline GG & $4(1.5)$ & $1(0.5)$ & $0.409(0.0443-0.799)$ & 0.431 & $1(0.7)$ & $0.597(0.061-5.833)$ & 0.657 \\
\hline $\begin{array}{l}\text { Dominant model } \\
\text { (TT versus GT + GG) }\end{array}$ & & & $1.274(0.777-2.088)$ & 0.377 & & $1.254(0.702-2.240)$ & 0.444 \\
\hline $\begin{array}{l}\text { Recessive model } \\
(\mathrm{TT}+\mathrm{GT} \text { versus GG) }\end{array}$ & & & $0.386(0.042-3.579)$ & 0.402 & & $0.568(0.058-5.534)$ & 0.626 \\
\hline $\mathrm{T}$ & $493(90.6)$ & $317(89.0)$ & 1.000 & & $230(89.8)$ & 1.000 & \\
\hline G & $51(9.4)$ & $39(11.0)$ & $1.177(0.746-1.855)$ & 0.484 & $26(10.2)$ & $1.183(0.693-2.018)$ & 0.538 \\
\hline
\end{tabular}

${ }^{\text {a }}$ ORs and $P$ values were obtained after adjusting for age, gender, smoking status, and wine status.

24]. SNPs in pre-miRNAs or mature miRNAs, especially in the seed region, may interfere with miRNA processing and maturation and affect the specificity of gene silencing [2527]. Aberrant expression of mature miRNAs or the alteration of their targets may contribute to the deregulation of relevant genes and finally lead to different cancer susceptibility, as well as different prognosis and treatment reaction [23]. Therefore, the identification of significant functional SNP sites may open a new avenue for HCC early diagnosis/predication.

MiR-646 belongs to miR-15/107 gene group which serves key functions in humans such as cell division, metabolism, stress response, and angiogenesis. Moreover, there is a seed sequence "AGCAGC" near the $5^{\prime}$ end of the mature miR-646 [28]. Particularly, the miR-646 SNP rs6513497, which is in the seed sequence, has been identified to be involved in the susceptibility to colorectal cancer $[15,28]$ and potentially to be used as a noninvasive biomarker for cervical squamous cell carcinoma [13]. The secondary structure prediction by miRNASNP database [16] showed that the structure of miR646 with the $\mathrm{T}$ allele of rs 6513497 has a $\Delta G$ of $-34.2 \mathrm{KJ} / \mathrm{mol}$, less than that with the $\mathrm{G}$ allele $(\Delta G=-33.4 \mathrm{KJ} / \mathrm{mol})$, indicating that $\mathrm{G}$ allele may decrease the stability of miR-646 and then result in the dysregulation of mature miR- 646.
Thus, in this study, we investigated the association between rs6513497 and the susceptibility to HCC and HBVrelated HCC in a large-scale population. Our findings support the view that rs6513497 was associated with HCC and HBV-related HCC. Furthermore, the protective effect of the variant genotypes of rs6513497 (GT genotype and the G allele) was more evident in male subjects, which decreases their HCC susceptibility. To the best of our knowledge, this is the first study to discover the association of miR-646 SNP with HCC susceptibility in clinical samples, suggesting that rs6513497 could be a useful marker to predict the risk of this disease. Further studies are required to explore the molecular function of this SNP. In addition, previous studies found that the SNPs of pri-miR-218 [29], miR-499 [30, 31], and miR$196 \mathrm{a} 2$ [32] were also associated with the risk of HCC. Their possible corporative effects and the underlying mechanisms are also worth being discovered.

Using TargetScan [33] and miRanda [34] database, we found that the potential predicated target genes of miR-646 consist of methylthioadenosine phosphorylase (MTAP), WEE1 G2 checkpoint kinase (WEE1), and cyclin D2 (CCND2), which are involved in the development of liver cancer. rs6513497 may influence the target selection 
TABLE 5: Clinicopathologic characteristics and genotype/allele frequencies of miR-646 rs6513497 in HCC patients.

\begin{tabular}{|c|c|c|c|c|c|c|c|}
\hline \multirow{2}{*}{$\frac{\text { Indexes }}{\text { Tumor size }}$} & \multicolumn{3}{|c|}{ Genotype } & $P$ value & \multicolumn{2}{|c|}{ Allele } & \multirow[t]{2}{*}{$P$ value } \\
\hline & & & & & & & \\
\hline miR-646 rs6513497 & $\mathrm{TT}$ & GT & GG & & $\mathrm{T}$ & G & \\
\hline$<5 \mathrm{~cm}$ & $180(84.1)$ & $35(16.9)$ & $0(0)$ & 0.713 & $395(31.9)$ & $35(68.1)$ & 0.617 \\
\hline$\geq 5 \mathrm{~cm}$ & $261(82.6)$ & $53(16.8)$ & $2(0.6)$ & & $575(34.3)$ & $57(65.7)$ & \\
\hline \multicolumn{8}{|l|}{ Tumor focus number } \\
\hline miR-646 rs6513497 & TT & GT & GG & & $\mathrm{T}$ & G & \\
\hline Single & $396(83.4)$ & $78(16.4)$ & $1(0.2)$ & 0.195 & $870(91.6)$ & $80(8.4)$ & 0.343 \\
\hline Multiple & $51(79.7)$ & $12(18.8)$ & $1(1.5)$ & & $114(89.1)$ & $14(10.9)$ & \\
\hline \multicolumn{8}{|l|}{ Tumor grade } \\
\hline miR-646 rs6513497 & TT & GT & GG & & $\mathrm{T}$ & G & \\
\hline I-II & $71(84.5)$ & $13(15.5)$ & $0(0)$ & 0.897 & $155(92.3)$ & $13(7.7)$ & 0.771 \\
\hline III-IV & $250(83.1)$ & $50(16.6)$ & $1(0.3)$ & & $550(91.4)$ & $52(8.6)$ & \\
\hline \multicolumn{8}{|l|}{ AFP } \\
\hline miR-646 rs6513497 & $\mathrm{TT}$ & GT & GG & & $\mathrm{T}$ & G & \\
\hline$<20 \mathrm{ug} / \mathrm{L}$ & $294(81.0)$ & $67(18.5)$ & $2(0.6)$ & 0.548 & $655(90.2)$ & $71(9.8)$ & 0.371 \\
\hline$\geq 20 \mathrm{ug} / \mathrm{L}$ & $511(83.5)$ & $97(15.8)$ & $4(0.7)$ & & $1119(91.4)$ & $105(8.6)$ & \\
\hline \multicolumn{8}{|l|}{ Total bilirubin } \\
\hline miR-646 rs6513497 & $\begin{array}{c}\mathrm{TT} \\
18.79 \pm 0.94\end{array}$ & $\begin{array}{c}\text { GT } \\
20.12 \pm 3.18\end{array}$ & $\begin{array}{c}\text { GG } \\
21.90 \pm 2.86\end{array}$ & 0.184 & & & \\
\hline \multicolumn{8}{|l|}{ Direct bilirubin } \\
\hline miR-646 rs6513497 & $\begin{array}{c}\text { TT } \\
8.78 \pm 0.70\end{array}$ & $\begin{array}{c}\mathrm{GT} \\
9.91 \pm 2.47\end{array}$ & $\begin{array}{c}\text { GG } \\
8.43 \pm 1.32\end{array}$ & 0.347 & & & \\
\hline \multicolumn{8}{|l|}{ Indirect bilirubin } \\
\hline miR-646 rs6513497 & $\begin{array}{c}\text { TT } \\
9.81 \pm 0.24\end{array}$ & $\begin{array}{c}\text { GT } \\
10.22 \pm 0.77\end{array}$ & $\begin{array}{c}\text { GG } \\
13.50 \pm 1.78\end{array}$ & 0.125 & & & \\
\hline \multicolumn{8}{|l|}{ ALT } \\
\hline miR-646 rs6513497 & $\begin{array}{c}\text { TT } \\
57.14 \pm 2.79\end{array}$ & $\begin{array}{c}\mathrm{GT} \\
59.92 \pm 7.51\end{array}$ & $\begin{array}{c}\text { GG } \\
51.38 \pm 8.13\end{array}$ & 0.643 & & & \\
\hline \multicolumn{8}{|l|}{ AST } \\
\hline miR-646 rs6513497 & $\begin{array}{c}\mathrm{TT} \\
62.17 \pm 2.78\end{array}$ & $\begin{array}{c}\mathrm{GT} \\
63.58 \pm 7.04\end{array}$ & $\begin{array}{c}\text { GG } \\
41.50 \pm 3.90\end{array}$ & 0.730 & & & \\
\hline \multicolumn{8}{|l|}{ HBV-DNA } \\
\hline miR-646 rs6513497 & $\begin{array}{c}\mathrm{TT} \\
1.73 E 06 \pm 2.85 E 05\end{array}$ & $\begin{array}{c}\mathrm{GT} \\
1.73 E 06 \pm 6.15 E 05\end{array}$ & $\begin{array}{c}\mathrm{GG} \\
2.93 E 06 \pm 1.68 E 06\end{array}$ & 0.526 & & & \\
\hline
\end{tabular}

of miR-646 and then alter HCC predisposition in the population with this SNP. Although there is no report or predictive record showing that targets have been gained or lost by rs6513497 so far, such speculation is still worth being explored.

In conclusion, the results of this study suggest that the miR-646 SNP rs6513497 is associated with HCC, and the G allele may be a genetic protective factor which decreases the susceptibility of HCC, especially in male subjects. To better understand the relationship between rs6513497 and cancer risk, more functional studies of miR-646 and this SNP are proposed.

\section{Conflict of Interests}

The authors declare that there is no conflict of interests regarding the publication of this paper.

\section{Authors' Contribution}

Rui Wang, Jun Zhang, and Weiru Jiang contributed equally to this work.

\section{Acknowledgments}

This work is supported by Grants from Ministry of Science and Technology of China (no. 2012CB910104) and National Natural Science Foundation of China (nos. 81300327 and 81201895). The funders have no role in study design, data collection and analysis, decision to publish, or preparation of the paper.

\section{References}

[1] A. Jemal, F. Bray, M. M. Center, J. Ferlay, E. Ward, and D. Forman, "Global cancer statistics," CA Cancer Journal for Clinicians, vol. 61, no. 2, pp. 69-90, 2011. 
[2] L. Gramantieri, F. Fornari, E. Callegari et al., "MicroRNA involvement in hepatocellular carcinoma," Journal of Cellular and Molecular Medicine, vol. 12, no. 6, pp. 2189-2204, 2008.

[3] M. Kertesz, N. Iovino, U. Unnerstall, U. Gaul, and E. Segal, “The role of site accessibility in microRNA target recognition," Nature Genetics, vol. 39, no. 10, pp. 1278-1284, 2007.

[4] C. L. Bartels and G. J. Tsongalis, "MicroRNAs: novel biomarkers for human cancer," Clinical Chemistry, vol. 55, pp. 623-631, 2009.

[5] E. A. Miska, "How microRNAs control cell division, differentiation and death," Current Opinion in Genetics and Development, vol. 15, no. 5, pp. 563-568, 2005.

[6] Y. Watanabe and A. Kanai, "Systems biology reveals microRNAmediated gene regulation," Frontiers in Genetics, vol. 2, article 29, 2011.

[7] Y. W. Jiang and L. A. Chen, "MicroRNAs as tumor inhibitors, oncogenes, biomarkers for drug efficacy and outcome predictors in lung cancer (review)," Molecular Medicine Reports, vol. 5, no. 4, pp. 890-894, 2012.

[8] P. S. Mitchell, R. K. Parkin, E. M. Kroh et al., "Circulating microRNAs as stable blood-based markers for cancer detection," Proceedings of the National Academy of Sciences of the United States of America, vol. 105, no. 30, pp. 10513-10518, 2008.

[9] X. Chen, Y. Ba, L. Ma et al., "Characterization of microRNAs in serum: a novel class of biomarkers for diagnosis of cancer and other diseases," Cell Research, vol. 18, no. 10, pp. 997-1006, 2008.

[10] J. Zhou, L. Yu, X. Gao et al., "Plasma microRNA panel to diagnose hepatitis B virus-related hepatocellular carcinoma," Journal of Clinical Oncology, vol. 29, no. 36, pp. 4781-4788, 2011.

[11] R. Duan, C. Pak, and P. Jin, "Single nucleotide polymorphism associated with mature miR-125a alters the processing of primiRNA," Human Molecular Genetics, vol. 16, no. 9, pp. 1124-1131, 2007.

[12] T. Xu, Y. Zhu, Q. Wei et al., "A functional polymorphism in the miR-146a gene is associated with the risk for hepatocellular carcinoma," Carcinogenesis, vol. 29, no. 11, pp. 2126-2131, 2008.

[13] W. T. Wang, Y. N. Zhao, J. X. Yan et al., "Differentially expressed microRNAs in the serum of cervical squamous cell carcinoma patients before and after surgery," Journal of Hematology \& Oncology, vol. 7, no. 1, article 6, 2014.

[14] J. M. Cummins, Y. He, R. J. Leary et al., "The colorectal microRNAome," Proceedings of the National Academy of Sciences of the United States of America, vol. 103, no. 10, pp. 3687-3692, 2006.

[15] R. Venkatachalam, E. T. P. Verwiel, E. J. Kamping et al., "Identification of candidate predisposing copy number variants in familial and early-onset colorectal cancer patients," International Journal of Cancer, vol. 129, no. 7, pp. 1635-1642, 2011.

[16] J. Gong, Y. Tong, H. Zhang et al., "Genome-wide identification of SNPs in MicroRNA genes and the SNP effects on MicroRNA target binding and biogenesis," Human Mutation, vol. 33, no. 1, pp. 254-263, 2012.

[17] R. W. Jun Zhang, Y. Ma, L. Chen et al., "Association between the single nucleotide polymorphisms in miRNA196a-2 and miRNA146a and susceptibility to hepatocellular carcinoma in a Chinese population," Asian Pacific Journal of Cancer Prevention, vol. 14, pp. 6427-6431, 2013.

[18] L. S. Zhang, W. B. Liang, L. B. Gao et al., "Association between pri-mir-218 polymorphism and risk of hepatocellular carcinoma in a han Chinese Population," DNA and Cell Biology, vol. 31, no. 5, pp. 761-765, 2012.
[19] Y. Zhang, H. Wu, J. Shen et al., "Predicting hepatocellular carcinoma by detection of aberrant promoter methylation in serum DNA," Clinical Cancer Research, vol. 13, no. 8, pp. 23782384, 2007.

[20] C. J. Chen and M. H. Lee, "Early diagnosis of hepatocellular carcinoma by multiple microRNAs: validity, efficacy, and costeffectiveness," Journal of Clinical Oncology, vol. 29, pp. 4745$4747,2011$.

[21] M. V. Iorio and C. M. Croce, "MicroRNA dysregulation in cancer: diagnostics, monitoring and therapeutics. A comprehensive review," EMBO Molecular Medicine, vol. 4, no. 3, pp. 143-159, 2012.

[22] L. R. Corsini, G. Bronte, M. Terrasi et al., "The role of microRNAs in cancer: diagnostic and prognostic biomarkers and targets of therapies," Expert Opinion on Therapeutic Targets, vol. 16, supplement 2, pp. S103-S109, 2012.

[23] O. Slaby, J. Bienertova-Vasku, M. Svoboda, and R. Vyzula, "Genetic polymorphisms and microRNAs: new direction in molecular epidemiology of solid cancer," Journal of Cellular and Molecular Medicine, vol. 16, no. 1, pp. 8-21, 2012.

[24] M. Lv, W. Dong, L. Li et al., "Association between genetic variants in pre-miRNA and colorectal cancer risk in a Chinese population," Journal of Cancer Research and Clinical Oncology, vol. 139, no. 8, pp. 1405-1410, 2013.

[25] S. Duan, S. Mi, W. Zhang, and M. E. Dolan, "Comprehensive analysis of the impact of SNPs and CNVs on human microRNAs and their regulatory genes," RNA Biology, vol. 6, no. 4, pp. 412425, 2009.

[26] M. S. Nicoloso, H. Sun, R. Spizzo et al., "Single-nucleotide polymorphisms inside microRNA target sites influence tumor susceptibility," Cancer Research, vol. 70, no. 7, pp. 2789-2798, 2010.

[27] B. M. Ryan, A. I. Robles, and C. C. Harris, "Genetic variation in microRNA networks: the implications for cancer research," Nature Reviews Cancer, vol. 10, no. 6, pp. 389-402, 2010.

[28] J. R. Finnerty, W. Wang, S. S. Hébert, B. R. Wilfred, G. Mao, and P. T. Nelson, "The miR-15/107 group of MicroRNA genes: evolutionary biology, cellular functions, and roles in human diseases," Journal of Molecular Biology, vol. 402, no. 3, pp. 491509, 2010.

[29] Y. Han, R. Pu, X. Han et al., "Association of a potential functional pre-miR-218 polymorphism and its interaction with hepatitis B virus mutations with hepatocellular carcinoma risk," Liver International, vol. 34, pp. 728-736, 2014.

[30] Y. Ma, R. Wang, J. Zhang et al., "Identification of miR-423 and miR-499 polymorphisms on affecting the risk of hepatocellular carcinoma in a large-scale population," Genetic Testing and Molecular Biomarkers, vol. 18, no. 7, pp. 516-624, 2014.

[31] H. Zou and Y. Zhao, "Positive association between miR-499A > $\mathrm{G}$ and hepatocellular carcinoma risk in a chinese population," Asian Pacific Journal of Cancer Prevention, vol. 14, no. 3, pp. 1769-1772, 2013.

[32] J. Zhang, R. Wang, Y. Y. Ma et al., "Association between single nucleotide polymorphisms in miRNA196a-2 and miRNA146a and susceptibility to hepatocellular carcinoma in a Chinese population," Asian Pacific Journal of Cancer Prevention, vol. 14, pp. 6427-6431, 2013. 
[33] B. P. Lewis, C. B. Burge, and D. P. Bartel, "Conserved seed pairing, often flanked by adenosines, indicates that thousands of human genes are microRNA targets," Cell, vol. 120, no. 1, pp. 15-20, 2005.

[34] B. John, A. J. Enright, A. Aravin, T. Tuschl, C. Sander, and D. S. Marks, "Correction: human microRNA targets," PLoS Biology, vol. 3, no. 7, article e264, 2005. 


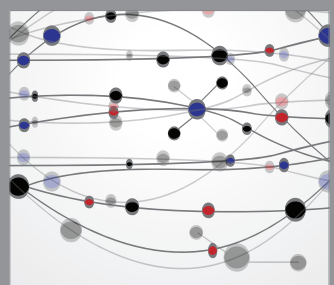

The Scientific World Journal
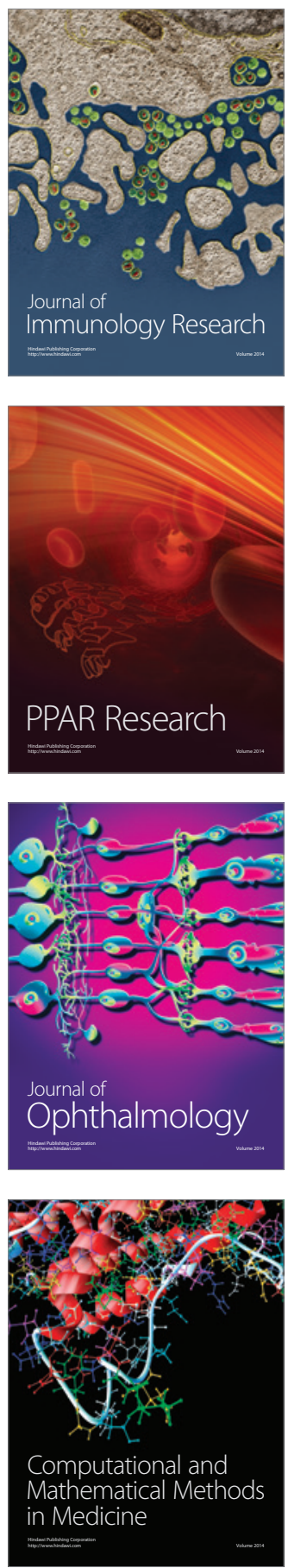

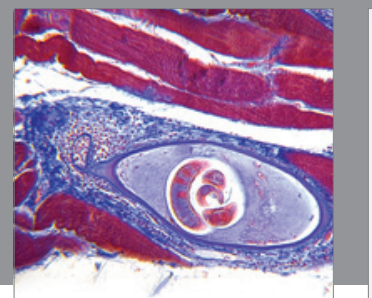

Gastroenterology

Research and Practice
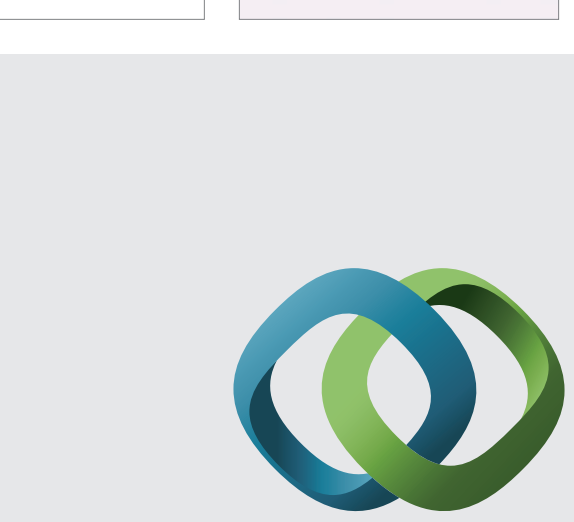

\section{Hindawi}

Submit your manuscripts at

http://www.hindawi.com
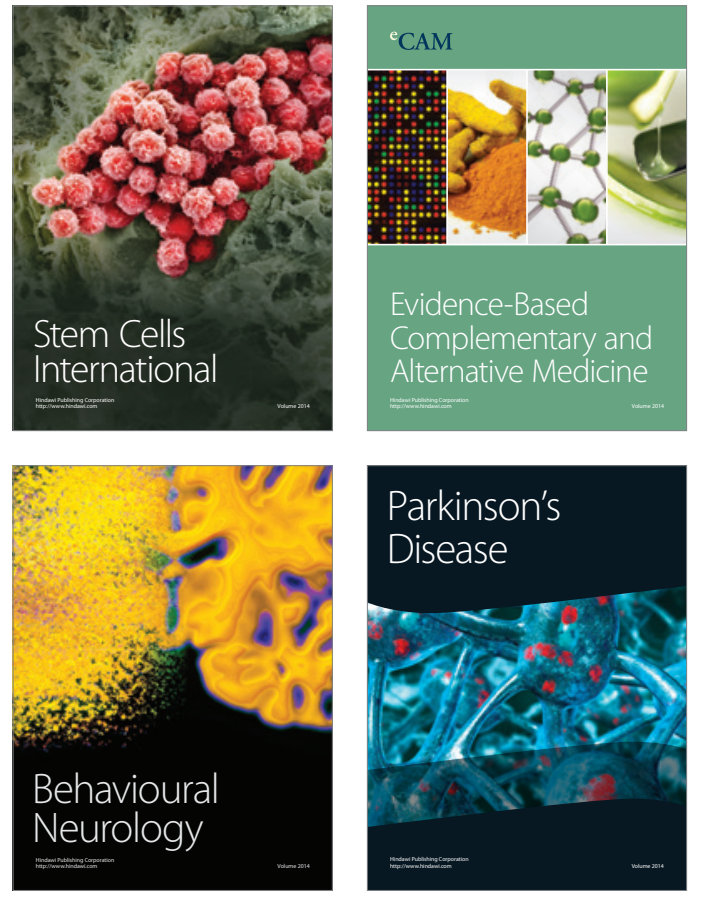
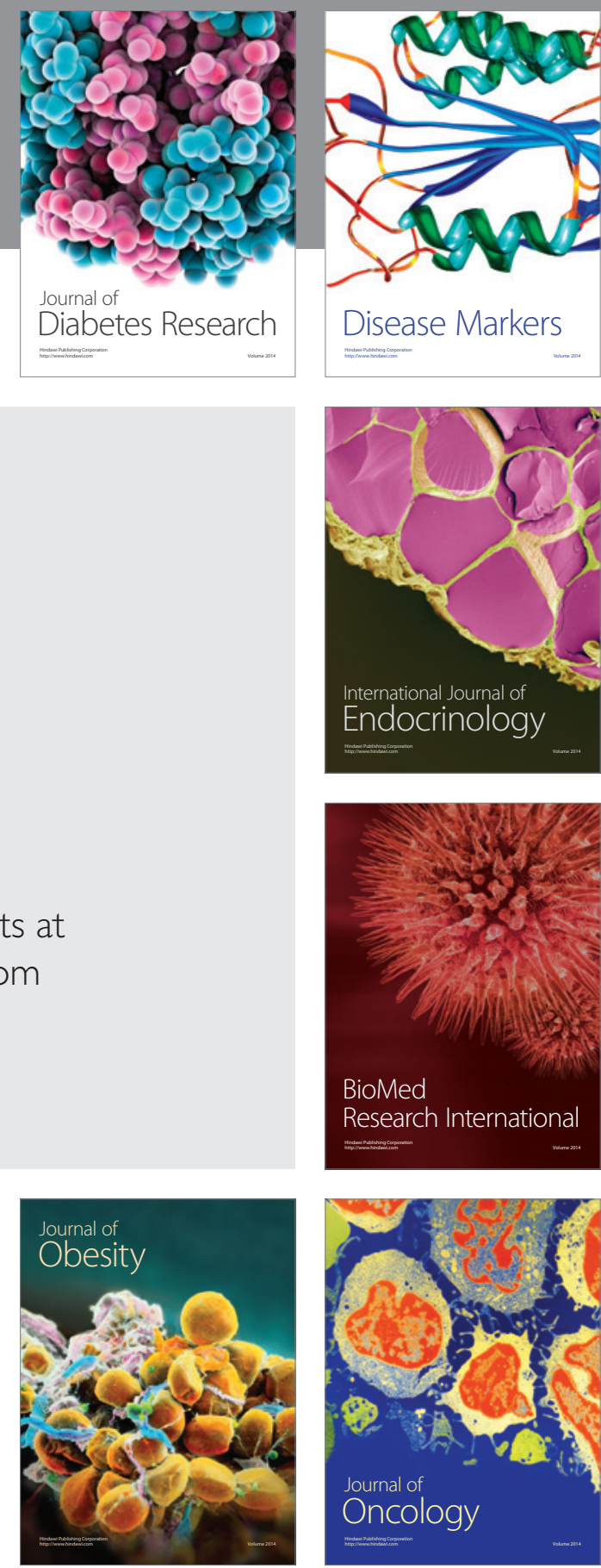

Disease Markers
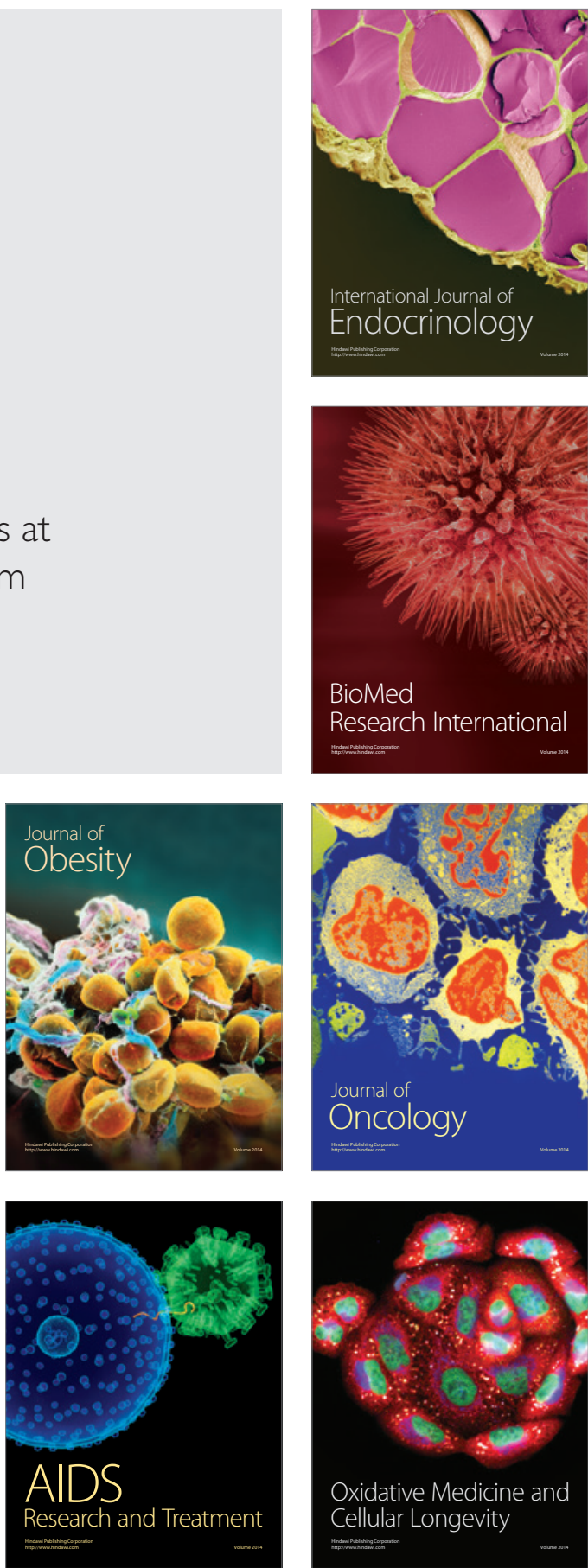